\title{
Cancer of the Transverse Colon: Comparison of Extended Right or Left Hemicolectomy versus Transverse Colectomy
}

\author{
Danilo Coco $^{1 *}$, Silvana Leanza ${ }^{2}$ \\ ${ }^{1}$ Ospedali Riuniti Marche Nord, Pesaro, Italy; ${ }^{2}$ Carlo Urbani Hospital, Jesi, Ancona, Italy
}

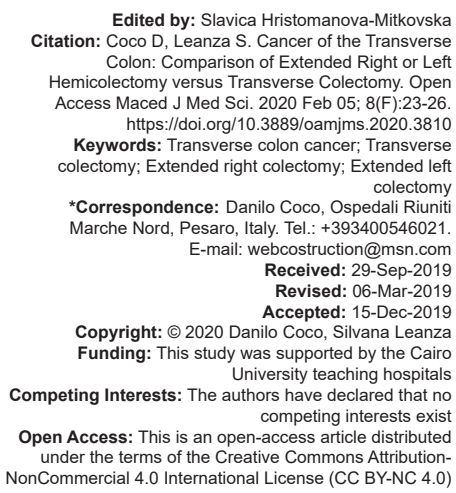

Edited by: Slavica Hristomanova-Mitkovska Citation: Coco D, Leanza S. Cancer of the Transvers Colon: Comparison of Extended Right or Left Hemicolectomy versus Transverse Colectomy. Open Access Maced J Med Sci. 2020 Feb 05; 8(F):23-26 https://doi.org/10.3889/oamjms.2020.3810 Keywords: Transverse colon cancer; Transverse colectomy; Extended right colectomy; Extended left *Correspondence: Danilo Coco, Ospedali Riunit Marche Nord, Pesaro, Italy. Tel.: +393400546021 E-mail: webcostruction@msn.com Revised: 06-Mar-2019 Accepted: 15-Dec-2019 Copyright: @ 2020 Danilo Coco, Silvana Leanza Funding: This study was supported by the Cairo Competing Interests: The authorsity teaching hospital Competing Interests: The authors have declared that no Open Access: This is an open-access article distributed under the terms of the Creative Commons Attribution-
NonCommercial 4.0 International License (CC BY-NC 4.0)

\begin{abstract}
The transverse colon is the part of colon between right and left colon from right flexure to splenic flexure. Standard surgical treatment involves either extended colectomy (EC) or transverse colectomy (TC), depending on the location of the tumor. The aim of the present study was to compare anastomotic leakage, hospital stay, operative time, overall complications rate, harvested nodes overall survival, and disease-free survival comparing EC versus TC.
\end{abstract}

\section{Objectives}

The transverse colon is the part of colon between right and left colon from right flexure to splenic flexure. The proximal two-thirds derive from mid-gut and the latter third derives from hind-gut. The proximal part is perfused by the middle colic artery that arises from superior mesenteric artery and the latter part is perfused by the left colic artery that is a branch of inferior mesenteric artery. The two parts of artery are joint with vascular anastomosis such as Riolano connection and are considered sensitive area of ischemia during colon-rectal surgery [1], [2]. The transverse colon is attached to the stomach by greater omentum; its mesentery is attached by the anterior surface of pancreas and is in close proximity with the liver, stomach, spleen, and pancreas. All these factors transform transverse colon cancer that accounts for only $10 \%$ of all colon cancer in a challenging procedure [1], [2] (Figure 1).

\section{Materials and Methods}

We have retrospectively evaluated PubMed articles. Fourteen studies were evaluated from 1995 to 2019. Six studies compared transverse colectomy (TC) versus extended colectomy (EC), including laparoscopic and open procedure. Eight studies included only laparoscopic procedures. Two independent researches performed the review. Research inclusion criteria were "transverse colon cancer, transverse resection, extended right colectomy, and extended left colectomy." The object of this retrospective study is to analyze anastomotic leakage, operative time, overall complications rate, harvested nodes, overall survival (OS), and disease-free survival (DFS) comparing EC versus TC.

\section{Outcomes}

Milone et al. revised five articles comparing extended right or left colectomy and transverse resection for transverse cancer, including 11,687 patients, 4664 transverse resection, and 7.023 EC. They found no statistical difference between the two groups for what concerns anastomotic leak, 5 years DFS, operative time, and length of stay. They noticed a statistically significant difference in favor of EC (MD $=-6.98$, $\mathrm{p}=<0.00001,95 \% \mathrm{Cl}-9.75,-4.20)$ in number of harvested nodes. A 5-year recurrence was reported with 


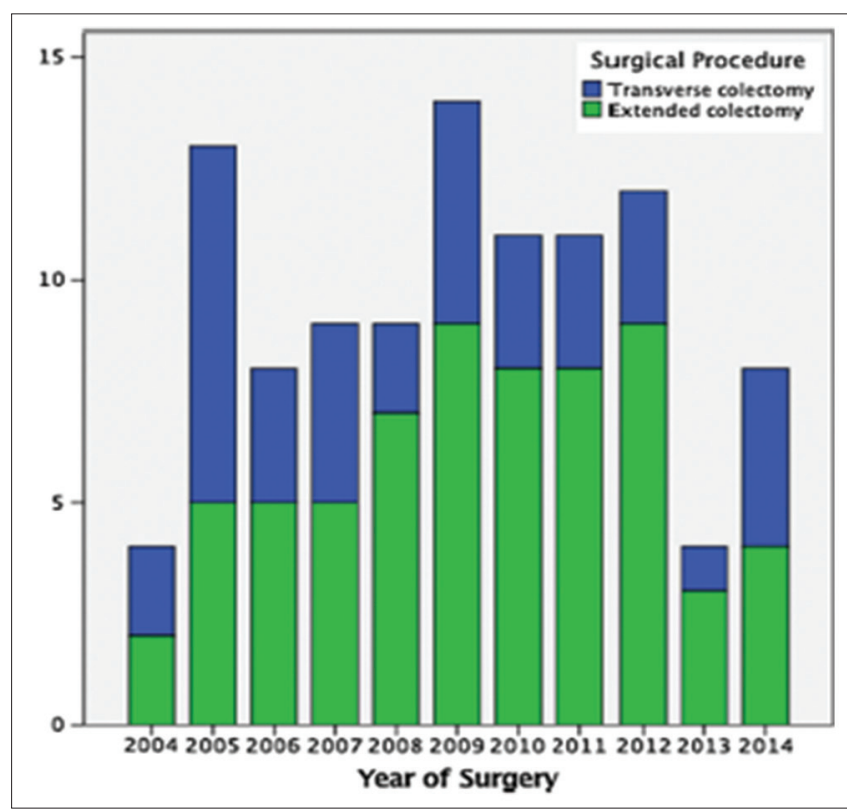

Figure 1: Incidence of different procedure of transverse colon cancer, from Lieve G.J

no statistically significant difference between the groups $(\mathrm{OR}=0.78, \mathrm{p}=0.38,95 \% \mathrm{Cl} 0.45,1.35)$ [1]. Leijssen et al. identified 103 patients who underwent a TC versus extended right or left colectomy (EC). Of 103 pt, 63\% underwent EC (right $47 \%$, left $17 \%$ ) and $37 \%$ TC. They
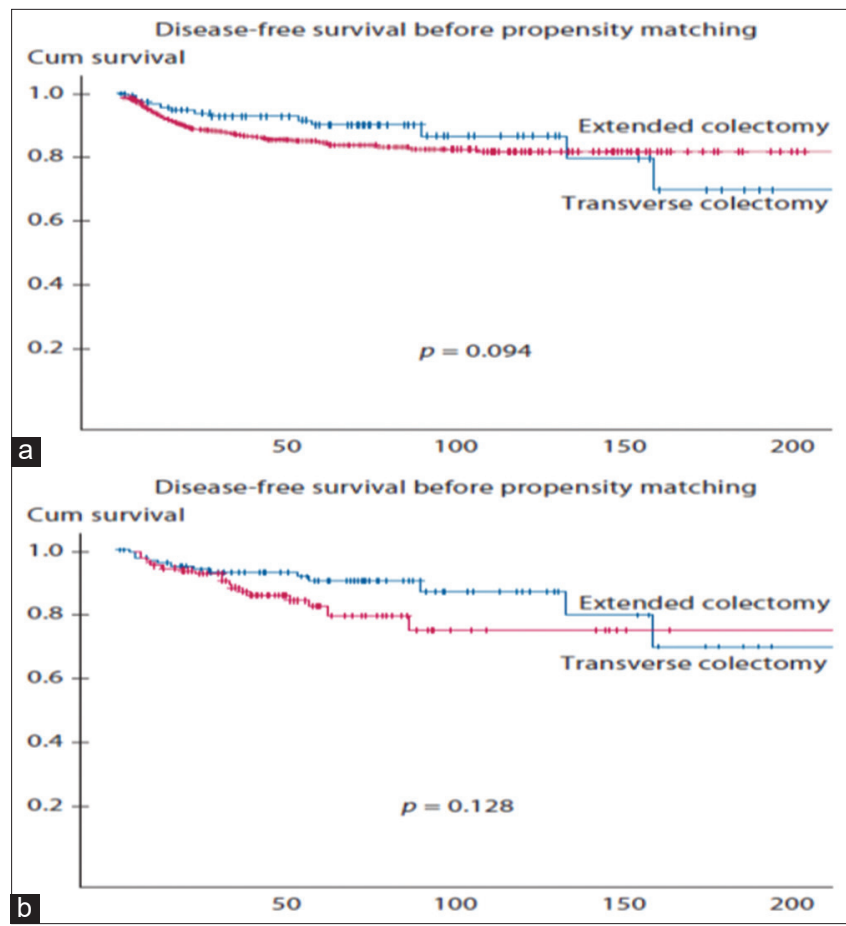

Figure 2: Disease-free survival plots before (a) and after (b) propensity score matching. Cum: Cumulative, DFS: Disease-free survival From Chong et al., diseases of the colon and rectum, 2016;59: 7.

noticed that OS and DSF were similar between the two groups but there were fewer lymph nodes harvested and worse short-outcomes in TC group. TC group was also correlated with poor histopathological features and disease recurrence [2]. van Rongen et al. have identified 103 patients, $34 \mathrm{TC} / 69 \mathrm{EC}$ derived from the database

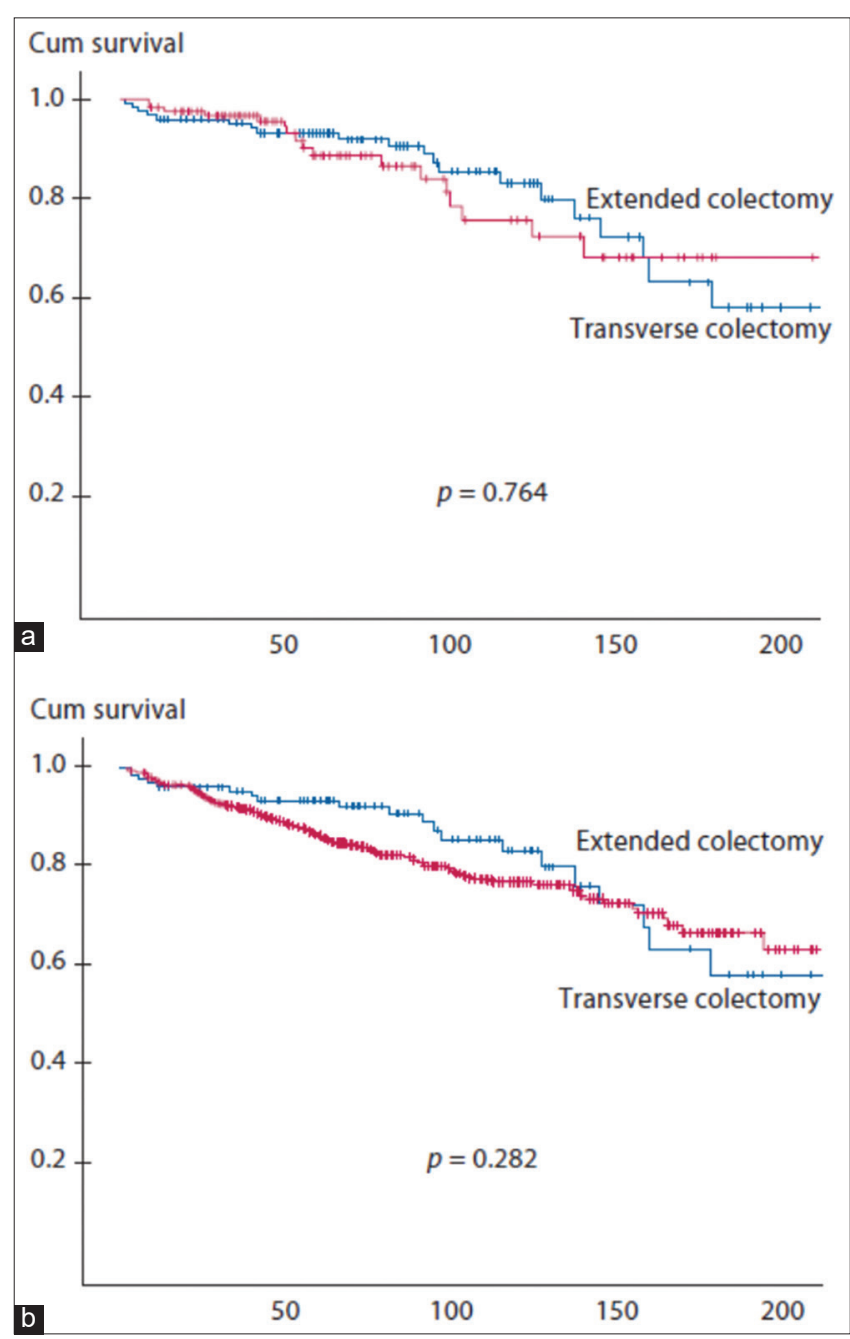

Figure 3: Overall survival plots before (a) and (b) propensi From Chong et al., diseases of the colon and rectum, 2016;59: 7.

of the regional cancer registry. They evidenced that the mean number of lymph nodes was slightly higher for patients treated by extended hemicolectomy $(p=0.20)$ and post-operative mortality was $6 \%$ after TC against $7 \%$ after extended hemicolectomy $(p=1.00)$. For TNM

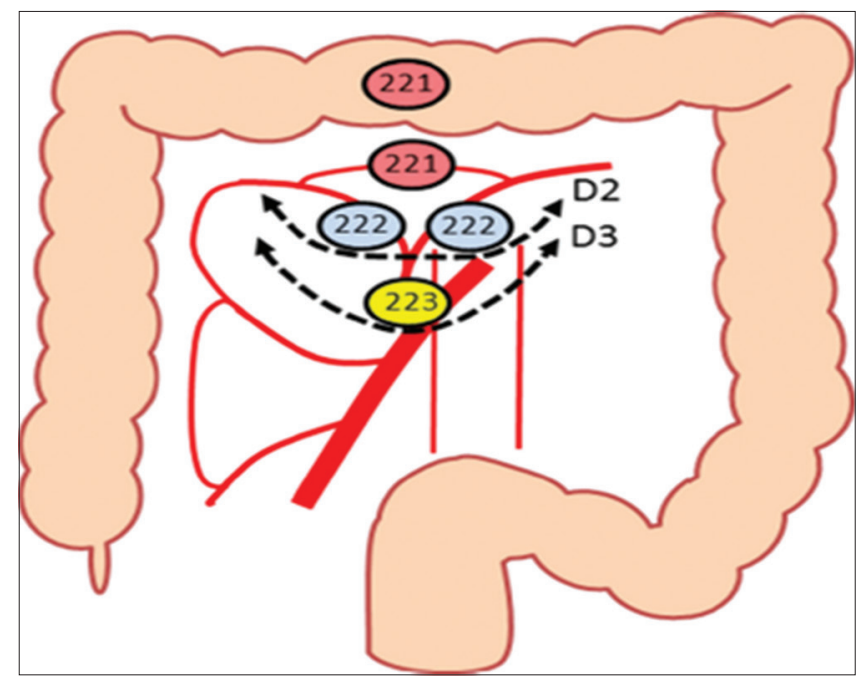

Figure 4: Lymph node mapping for transverse colon cancer according to the Japanese Society of colorectal surgeons 
Table 1: Cumulative results of the published literature about the comparison of extended right or left hemicolectomy versus transverse colectomy in the cancer of the transverse colon

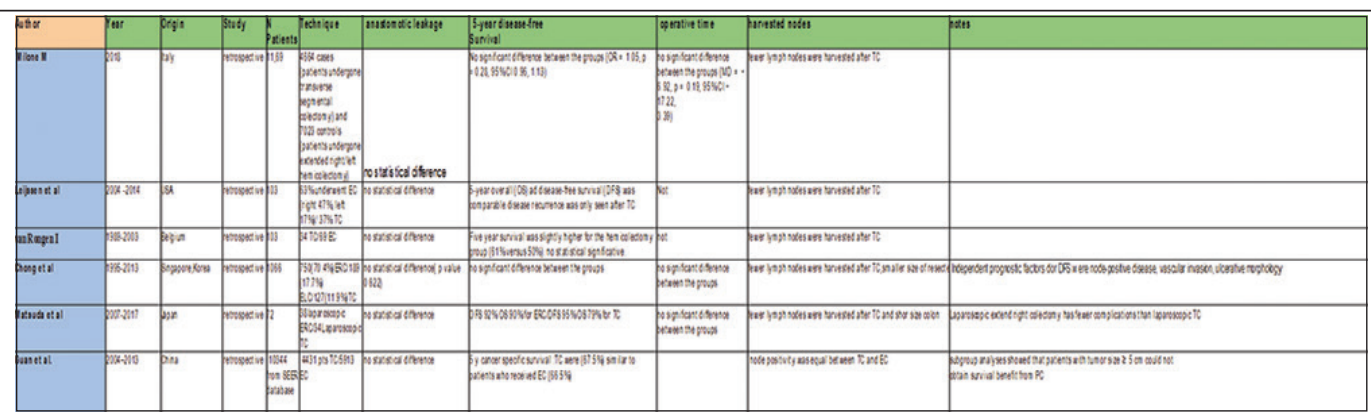

stages I-II, 5-year survival was slightly higher for the hemicolectomy group (65\% vs. $55 \%$ ) but this difference did not reach statistical significance $(p=0.38$, hazard ratio $1.4,95 \% \mathrm{Cl} 0.6-3.1$ ). For TNM stage III, 5-year survival was also higher for the hemicolectomy group $(52 \%$ vs. $42 \%)$, but again not significantly ( $p=0.82$, hazard ratio $1.1,95 \% \mathrm{Cl} 0.4-2.9)$. They preferred to propose TC technique and they suggested that segmental resections of the transverse colon can be performed at an acceptable risk with satisfactory survival outcome [3]. Matsuda et al. performed a retrospective study of their center from 2007 to 2017 comparing laparoscopic endoscopic retrograde cholangiography (LERC) versus laparoscopic total colectomy (LTC). They found similar DFS and OS, similar anastomotic leakage but fewer general complications in LERC, fewer harvested nodes, and colon size in LTC [4]. Chong et al. have proposed a retrospective study, included 1.066 patients with transverse colon cancer, of whom $70 \%$ received ERC, $17 \%$ ELC, and $11 \%$ TC. They noted that there is no difference about OS and DFS between the two groups, underlying that TC must be reserved for old patients or patients with extended pathology or for small transverse tumors. TC had lower harvested lymph nodes (LNs) and small size of colon resection. Independent prognostic factors for DFS were node-positive disease, vascular invasion, and ulcerative morphology (Figures 2 and 3) [5]. Guan et al. found inferior number of harvested nodes in transverse resection but similar rate of nodes positivity between transverse resection and EC. They said that the 5-year cancer-specific survival for patients with transverse resection was similar to patients who received extended colectomy [6] To conclude, many studies also compare laparoscopic versus open TC and EC, underlying similar short- and long-term outcomes for both procedure [7], [8], [9], [10], [11], [12], [13], [14] (Table 1).
TC cancer has various number of technical description but lacks about indications of real gold standard technique. Due to the risk of vascular insufficiency and for the anatomical location in proximity of superior mesenteric artery and technical difficulties to splenic and hepatic flexure takedown, TC and EC are two challenging procedures. Conservative treatment using TC is safe and has similar oncological results and postoperative complications compare to EC. The studies underline a superior number of harvested nodes with EC with similar 5 years oncological outcomes but lack in results about anastomotic leakage. The length of the specimen, the number of harvested nodes, perineural, and vascular invasion can influence OS and DFS in favor of EC. Park et al. reported only $10 \%$ of occurred lymph node metastasis in the right colic artery and no metastasis in ileocolic vessels [15]. ERC was performed to have a minor risk of anastomotic leakage, fewer difficulties in the technique to avoid splenic flexure takedown that is necessary in TC and to have a large margin to cancer and more harvested LFN. Section of right colic artery and ileocolic artery should be unnecessary. This means that D2 LFN versus D3 LFN in Japanese classification does not have any difference in DFS and OS (Figure 4). For more results, it is necessary defining traverse colon tumor as a tumor of mid-transverse colon or on the right or left splenic flexure too and prospective trials with inclusion and exclusion criteria are needed to have clear oncological results and post-operative complications [2].

\section{Human Rights Statement} standards

All procedures and experiments met the ethical

\section{References}

Transverse colon cancer has a 5-year survival rates of $25-50 \%$ which is significantly poorer outcome compared with cancers in the other part of the colon [5]
1. Milone M, Manigrasso M, Elmore U, Maione F, Gennarelli N, Rondelli $\mathrm{F}$, et al. Short-and long-term outcomes after 
transverse versus extended colectomy for transverse colon cancer. A systematic review and meta-analysis. Int $\mathrm{J}$ Colorectal Dis. 2019;34(2):201-7. https://doi.org/10.1007/ s00384-018-3186-4

PMid:30402767

2. Leijssen LG, Dinaux AM, Amri R, Kunitake H, Bordeianou LG, Berger DL. A transverse colectomy is as safe as an extended right or left colectomy for mid-transverse colon cancer. World J Surg. 2018;42(10):3381-9. https://doi.org/10.1007/ s00268-018-4582-1

PMid:29556881

3. van Rongen I, Damhuis RA, van der Hoeven JA, Plaisier PW. Comparison of extended hemicolectomy versus transverse colectomy in patients with cancer of the transverse colon. Acta Chir Belg. 2013;113(2):107-11. https://doi.org/10.1080/0001545 8.2013.11680895

PMid:23741929

4. Matsuda T, Sumi Y, Yamashita K, Hasegawa H, Yamamoto M, Matsuda Y, et al. Optimal surgery for mid-transverse colon cancer: Laparoscopic extended right hemicolectomy versus laparoscopic transverse colectomy. World J Surg. 2018;42(10):3398-404. https://doi.org/10.1007/s00268-018-4612-z

PMid:29610931

5. Chong CS, Huh JW, Oh BY, Park YA, Cho YB, Yun SH, et al. Operative method for transverse colon carcinoma: Transverse colectomy versus extended colectomy. Dis Colon Rectum. 2016;59(7):630-9. https://doi.org/10.1097/dcr.0000000000000619 PMid:27270515

6. Guan X, Zhao Z, Yang M, Chen H, Chen W, Liu Z, et al. Whether partial colectomy is oncologically safe for patients with transverse colon cancer: A large population-based study. Oncotarget. 2017;8(54):93236-44. https://doi.org/10.18632/ oncotarget.21275

PMid:29190993

7. Akiyoshi $T$, Kuroyanagi $H$, Fujimoto $Y$, Konishi $T$, Ueno $M$, Oya M, et al. Short-term outcomes of laparoscopic colectomy for transverse colon cancer. J Gastrointest Surg. 2010;14(5):818-23. https://doi.org/10.1007/s11605-010-1182-2

PMid:20224982

8. Fernández-Cebrián JM, Gil Yonte $P$, Jimenez-Toscano $M$, Vega L, Ochando F. Laparoscopic colectomy for transverse colon carcinoma: A surgical challenge but oncologically feasible. Colorectal Dis. 2013;15(2):e79-83. https://doi.org/10.1111/ codi. 12067

\section{PMid:23078032}

9. Hahn KY, Baek SJ, Joh YG, Kim SH. Laparoscopic resection of transverse colon cancer: Long-term oncologic outcomes in 58 patients. J Laparoendosc Adv Surg Tech A. 2012;22(6):5616. https://doi.org/10.1089/lap.2011.0422 PMid:22690652

10. Hirasaki Y, Fukunaga M, Sugano M, Nagakari K, Yoshikawa S, Ouchi M. Short-and long-term results of laparoscopic surgery for transverse colon cancer. Surg Today. 2014;44(7):1266-72. https://doi.org/10.1007/s00595-013-0682-6

PMid:23934542

11. Kim HJ, Lee IK, Lee YS, Kang WK, Park JK, Oh ST, et al. A comparative study on the short-term clinicopathologic outcomes of laparoscopic surgery versus conventional open surgery for transverse colon cancer. Surg Endosc. 2009;23(8):1812-7. https://doi.org/10.1007/s00464-009-0348-z PMid: 19263150

12. Lee YS, Lee IK, Kang WK, Cho HM, Park JK, Oh ST, et al Surgical and pathological outcomes of laparoscopic surgery for transverse colon cancer. Int J Colorectal Dis. 2008;23(7):669-73. https://doi.org/10.1007/s00384-008-0471-7 PMid:18379794

13. Zhao L, Wang $\mathrm{Y}$, Liu $\mathrm{H}$, Chen $\mathrm{H}$, Deng $\mathrm{H}$, Yu J, et al. Longterm outcomes of laparoscopic surgery for advanced transverse colon cancer. J Gastrointest Surg. 2014;18(5):1003-9. https:// doi.org/10.1007/s11605-014-2462-z

PMid:24449001

14. Zmora O, Bar-Dayan A, Khaikin M, Lebeydev A, Shabtai M, Ayalon A, et al. Laparoscopic colectomy for transverse colon carcinoma. Tech Coloproctol. 2010;14(1):25-30. https://doi. org/10.1007/s10151-009-0551-x

PMid:20033245

15. Park IJ, Choi GS, Kang BM, Lim KH, Jun SH. Lymph node metastasis patterns in right-sided colon cancers: Is segmental resection of these tumors oncologically safe? Ann Surg Oncol. 2009;16(6):1501-6. https://doi.org/10.1245/s10434-009-0368-x PMid:19252953 